\title{
The work-life balance of employees and management staff working for newly established virtual organisation as a result of the COVID-19 Pandemic
}

\author{
Luka de Wet; Student
}

Seugnet Bronkhorst

University of Johannesburg, South Africa

\begin{abstract}
Keywords
Work-life Balance, Virtual Groups, Covid-19, Working from home, Qualitative research, Conceptual Paper
\end{abstract}

\begin{abstract}
Purpose of the research: The purpose of the research was to determine whether the establishment of, and transformation to, virtual organisations due to the COVID-19 pandemic restrictions placed on the business sector, impacts drastically on the work-life balance of new virtual employees. Design/methodology: A positivist, qualitative research that draws on a descriptive research design was used in order to provide a conceptual understanding of the impact on work-life balance that has been caused by a shift to virtual organisations as a result of the COVID-19 pandemic.

Results/findings: The restrictions placed on the business sector as a result of the COVID-19 pandemic resulted in the establishment of, and transformation to, virtual organisations. This had a drastic impact on the work-life balance of new virtual employees. The findings indicated varying opinions and understandings on work-life balance for virtual employees concluded prior to the pandemic.

Practical implications and Conclusions: The recognition of drastic impact on the work-life balance of new virtual employees should be recognised by businesses and taken into consideration when dealing with employees.

Limitations: The study was limited to only conceptual research. Further quantitative research will lead to additional, inclusive, knowledge
\end{abstract}

\section{Introduction}

The aim of this research is to determine the emphasis that virtual organisations place on the work-life balance of their employees and management staff.

Due to the COVID-19 pandemic, there has been an increase in the establishment, and transformation to, virtual organisations. As a result of restrictions and regulations, a limitation on the number of people allowed in a confined space is in place.

Virtual organisations offer many advantages in relation to the work-life balance of employees as it allows for balancing work and personal commitments (Jya \& Shenoy, 2018:2). According to Deeb (2020:6) employees save time on travel and function in a work environment personally catered for themselves. However, employees working for companies adopting the practices of virtual organisations may find themselves in a position where their workspace and their leisure-space are the same and have to adapt to this way of work (Goodman, 2021). It becomes difficult for employees to separate their work-life balance in an environment where they are intertwined (Goodman, 2021). Goodman (2021) adds that clear boundaries need to be established to avoid a disturbance in the work-life balance of employees. This may result in employees experiencing difficulties in relation to knowing when to stop working, which leads to longer hours and greater work-related stress (Arntz, Berlingieri \& Sarra, 2019:4).

\section{Background and rationale}

A virtual organisation consists of employees located in different geographical areas, communicating through technological sources such as phones, email, and the internet (Kerwin \& Radulovic, 2018:54). These organisations have been defined over three decades since the establishment of the dotcom 
companies' era in the early nineties (Amorim, 2007). The companies are in a unique position in that their employees work virtually (away from an office setting) at a location of their choice. The distinguished advantages and disadvantages of virtual organisation are: and

The advantage of flexibility that virtual organisations offer (Leimeister, Weigle \& Krcmar, 2001:7),

The disadvantages such as the uncertainty around what is happening in an employee's home space that might affect his/her productivity and work-life balance (Hansen et al., 2021:5).

Many virtual organisations were established in the early part of 2020, due to the COVID-19 pandemic resulting in regulations that restricted the number of people allowed in buildingsoffices at one given time (Feitosa \& Salas, 2020). This resulted in employees taking on a new work environment (such as their home) and performing their tasks remotely from these locations (Butahieko \& Vyas, 2020:64).

It should be noted that employees working for newly established virtual organisations, as a result of the COVID-19 pandemic, were not prepared to work under this organisational structure, which has created further challenges in their ability to balance their work-life and their home-life.

\subsection{Problem statement}

Due to the COVID-19 Pandemic, many organisations have transformed from brick-and-mortar companies to online/virtual organisations. As a result, employees are now free to work from a location of their choice. This freedom of choice comes with the unclear distinction between the balance of work-life and personal-life, as it is difficult for employees to develop boundaries due to their location of choice now being their office environment, additionally making it challenging to recognise standard working hours. The problem statement can therefore be identified as determining the work-life balance of employees due to virtual organisations, as a result of the COVID-19 pandemic.

\section{Research objectives}

Primary objective

The primary objective of this study is to determine how the work-life balance of employees within virtual organisations, due to COVID-19 regulations, are influenced.

Secondary objectives

To determine the benefits of working virtually during the COVID-19 pandemic, prevalent to newly established virtual employees.

To determine the challenges of working virtually during the COVID-19 pandemic, prevalent to newly established virtual employees.

To determine if the change from an office setting to a home setting in a virtual organisation induced further stress and family conflict on employees.

To determine whether employees that form part of virtual organisations are as productive as brickand-mortar organisations.

\section{Literature Review}

\subsection{Introduction}

This literature review will give context to the research question pertaining to virtual organisations by looking into and analysing the literature currently available in relation to these types of companies.

\subsection{Definition of a virtual organisation / virtual work}

The understanding of what a virtual organisation actually is remains without a clearly outlined definition within academic literature. This is due to the constant evolution of such companies. Nevertheless, there are various characteristics and aspects of these organisations, and the manner in which they perform their work, that authors consider when elaborating on the fundamentals of virtual work. Authors consider virtual organisations to be entities that are established for a limited period of time, wherein the participants of that organisation are usually geographically distributed (Chumg, Seaton \& Cooke, 2016:32). Alawamleh and Ismail (2016:8) refers to a virtual organisation as being "a permanent or temporary collection of geographically dispersed individuals, groups, organisational units (who may or 
may not belong to the same organisation) that depend on technology and electronic linking in order to complete the production process of the joint work conducted by these units".

\subsection{Aspects of virtual organisations}

There are various aspects and common features that are prevalent in relation to virtual organisations. These include the members and employees of virtual organisations being geographically dispersed and not working in central office space. Furthermore, virtual organisations are heavily reliant on technology and Information and Communication Technologies and are considered to be boundaryless while having unique organisational structures and increased flexibility. These aspects will be discussed below.

\subsubsection{Geographically dispersed}

According to Alawamleh and Ismail (2016:29), one of the necessary structural conditions that is needed for a virtual organisation to exist is the geographical dispersion of organisational units that are therefore not working in a central office space. An organisation is only considered to be spatially dispersed where members of the virtual organisation (individuals, divisions or groups) are dispersed at a minimum of two separate locations (Alawamleh \& Ismail, 2016:29). This aspect is viewed to be most important when it comes to identifying if an organisation is considered to be one which is virtual, as the networking orlinking of individuals, divisions, and even entire organisations, has to be done in a manner that is geographically remote from one another in order for it to be considered virtual work or virtual business practices (Bajdor, Dagmara \& Lis, 2016:3).

The benefits that come with members of virtual organisations being geographically dispersed, include:

The organisation's ability to employ talented and diverse employees from any country, as the search for employees is not confined to the geographic location of the organisation (Domazet, Radović \& Brandić, 2018:61).

The hiring of low-cost, but qualified, labour force from geographic areas where the labour cost is low (Domazet et al., 2018: 61).

The luxury of competing in global markets without a concern about geographical restrictions to their business practices (Dulebohn \& Hoch, 2017: 573).

There are, however, various drawbacks that come with the members of virtual organisations being geographically dispersed:

Domazet et al., (2018: 62) express concerns over the restriction of face-to-face interactions that comes with virtual organisations

The authors further indicate the possibility for breakdowns in communication as a result of cultural differences that exist between the members located in different geographic regions.

\subsubsection{Reliant on technology and ICT}

Due to the geographical dispersion of employees, Information Technology (IT) is placed in a central role and is considered to be the driving factor in how virtual organisations are able to operate (Messenger \& Gschwind, 2016: 197). Virtual organisations make use of information and communication technologies (ICT) to:

Aid the coordination and communication of members and activities performed for the company.

view the progress of team members, with whom they cannot make physical contact with (Waizenegger et al., 2020: 429); and

succeed and operate telecommunications (which have made distance irrelevant), databases (which provide a virtual organisational memory, making time irrelevant), and multimedia (Messenger \& Gschwind (2016:205).

Virtual organisations are often described as those that heavily make use of various technologies (specifically Information Technologies) in order to reduce common restrictions pertaining to geography, time and information that an organisation may face. However, technologies are constantly evolving, and newly developed technologies are not always universally available. The virtual organisations need to 
constantly adapt to these new technologies and ICT systems in order to maintain a virtual presence and provide easy access to their members (Jimenez et al., 2017:5).

\subsubsection{Boundaries and borders of virtual organisations}

New boundaries need to be established by the virtual organisation in order to separate members of the organisation, as these virtual organisations do not have traditional physical boundaries (Čulo, 2016:36). This is done through the establishment and implementation of technological boundaries to ensure the sanctity of the organisation. This results in non-member not being able to enter. Messenger and Gschwind (2016: 204) contend that virtual organisations could establish boundaries through passwords, ID's, coded language, and even a specific computerised mailing list to which only the members of the organisation are part of and have access to.

An organisation is considered to be more virtual if its boundaries are more invisible. This would be a result of the technologies used (Grubb, 2021: 6). For instance, a physical entrance to a filing room that is only accessible by an employee's key card is far less virtual than an organisation protecting its virtual files using a firewall or online server.

Virtual organisations are often referred to as boundary-less organisations (Bui, 2020: 20). This is in reference to organisations that are considered not to have walls or limits, and those that are made more flexible as a result of the traditional boundaries of hierarchy, function and geography being eradicated within these virtual organisations (Čulo, 2016:36). Due to technology and ICT systems, virtual organisations transcended across geographical distances and organisational boundaries (Bui, 2020: 9). This resulted in unique business models and practices.

According to Domazet et al. (2018:57) one of the major characteristics of a virtual organisation is the permeable boundaries, referring to the quantity of new information that may be accessed by members of the organisation. This indicates the lack of rigid and systematic boundaries and would allow for more information to be accessed by its members (through systems such as ICT), resulting in a lesser degree of confined information. Jimenez et al. (2017:1) conferred working across organisational boundaries, specifically in terms of the labour force, as not an exception within virtual organisations, but rather considered to be the norm. Members of virtual organisations include full-time and part-time employees as well as contractors, suppliers and freelancers operating independently from the virtual organisation but conform to the same goal and business functions.

\subsubsection{Organisational structure of virtual organisations}

Due to the unique nature in which virtual organisations operate, the actual organisational structure needs to be different. Although different views exist on the organisational structure of a virtual organisation, the general consensus is that the overall structure pertains to the ability for it to be flexible. The majority of authors, since the emergence of literature pertaining to virtual organisations in the 1990's, viewed existing organisational structures as obsolete due to traditional organisational structures obstructing the true value and nature of Information and Communication Technology that virtual organisations promote. Even though the aforementioned organisational structures were viewed as obsolete, people had to rely on an incremental implementation of virtual organisations that still reflected the traditional organisational structure, rather than an instant change (Alawamleh \& Ismail, 2016: 31).

Virtual organisations make use of various organisational structures and combine these structures in order to create new organisational capabilities and competencies, which allows for overhead costs and other structures to be kept to a minimum. This results in the efficiency of administrative work that the virtual organisation emphasises (Čulo, 2016:35). Domazet et al. (2018:69) state that the corporate structure of a virtual organisation is almost entirely egalitarian. The job responsibilities and power of employees are:

shared equally,

highly specific job descriptions, and

guided by a common purpose. 
Virtual organisations are far less rigidly structured compared to classical or traditional organisations (Bajdor et al., 2016:3). With virtual organisations placing such an importance on flexibility in terms of its structure, Culo (2016:37) indicates that there are important factors that enable this flexibility to work within a virtual organisation, including:

the trust among the partners of the organisation being vital as there is a lesser degree of a traditional hierarchy.

the ability to build and develop flexible work teams; and

the communication, coordination and cooperation required.

The organisational structure of a virtual organisation is generally horizontal (Chumg et al., 2016:9). This echoes what has been stated in the literature above in terms of the flexibility within the organisational structure, as well as the decrease of a traditional hierarchal organisational structure (known as a vertical structure) that occurs in traditional organisations.

\subsubsection{Increased flexibility within a virtual organisation}

Virtual organisations are flexible in the ability to exist without physical limits or walls, as well as expelling the traditional boundaries of hierarchy, function and geography which, in turn, creates more flexibility in relation to the organisational structure of the virtual organisation (Walzenegger et al., 2020:432). This is emphasised by Domazet et al. (2018: 68), who states that virtual organisations do not have to worry about barriers such as place and time. However, an important aspect of the flexibility within virtual organisations that needs to further be elaborated on, is that of their virtual teams and virtual members.

According to Anthony and Petersen (2021:628), staffing arrangements are more flexible within virtual organisations, as employees are not fixed to a certain space-limit within the organisation, or geographic location. This flexibility results in lower overhead costs as employers do not have to provide office space for these employees. Further to this, virtual organisations could hire a low-cost but qualified labour force from geographic areas where the labour cost is low (Domazet et al., 2018:61).

Flexible working arrangements afforded to virtual workers would:

influence productivity and employee commitment,

ultimately reduce stress,

provide more flexibility, and

provide better work-life balance towards these employees (Shenoy, 2020:2).

have a more flexible schedule and greater comfort (as they are working from a location of their choice), and

save on travel expenses, due to the fact that they are not travelling to an office every day (Shenoy, 2020:2; and Zuofa \& Ochieng, 2017:5).

Another important characteristic of a virtual organisation is its ability to react flexibly to market changes (Alawamleh \& Ismail, 2016:29). This is achieved through less standardised internal processes, due to the nature of the organisational structure within a virtual organisation being less hierarchal, more horizontal, and employee tasks being more general in nature (Chumg et al., 2016: 9; Domazet et al., 2018:69). Therefore, virtual organisations can react quickly and more beneficially to more dynamic business and client requirements (Zuofa \& Ochieng, 2017:5).

\section{Research Methodology}

\subsection{Research paradigm}

The study will use positivism as a research paradigm. Positivism applies natural science methods to social science and business research, in order to study the social reality of what is being observed (Ryan, 2018:4). Hence, to establish an objective truth, this scientific method is deemed the best as this paradigm views the world as having a single reality. Objectivity is the collective theme that runs through the positivism paradigm. The positivism paradigm is the best alternative, as the research is not establishing new understandings and norms, as would be the case in grounded theory research. The contribution from this study aims to establish an understanding and form an overall view of the combined literature on the 
nature of virtual organisations' effect on the work-life balance of employees. This research is aiming to determine the effect on the work-life balance of employees' party to newly established virtual organisations as a result of the COVID-19 pandemic. The existing literature on virtual organisations and their operations before the pandemic will be analysed. A further analysis will be made on the impact that the COVID-19 pandemic has had on the commerce sector, which forced many organisations to adopt a virtual structure.

\subsection{Nature of research}

This research study is qualitative in nature. Qualitative research refers to an iterative process wherein an improved understanding of a topic is achieved, through the establishments of significant distinctions as a result of analysing the phenomenon being studied (Aspers \& Corte, 2019:155). This research study is entirely conceptual and is based on analysing literature on virtual organisations, as well as the constant, new inflow of current literature that is being established on the effects of the COVID-19 pandemic. Further, the aim of this research is to reach and provide an understanding of the work-life balance or virtual teams during the pandemic, meaning that it aims to improve the understanding that is novel to the scholarly community, of a phenomenon being studied, which further indicates the qualitative nature of the research. This contribution is a literature study based on the current literature that is available in relation to the work-life balance of employees during the COVID-19 pandemic.

\subsection{Research design}

This research study is descriptive research design following the same methodology as a conceptual research study. A descriptive research design is non-experimental in nature, as it aims to describe a phenomenon that has occurred or is occurring (Siedlecki, 2020:8). In descriptive research, no variables are manipulated, and are rather observed and described (Siedlecki, 2020:8). The aim of this research study is to describe phenomena, being the work-life balance of virtual employees during the COVID-19 pandemic, which will be done by analysing various forms of literature.

There will be no interviews, nor experimental studies conducted in this research, as the research is solely conceptual and descriptive. Jaakkola (2020:19) states that conceptual research does not derive its conclusion from raw data, as it involves assessing and analysing a combination of evidence to a phenomenon, based off on previously developed concepts and theories. Therefore, conceptual studies are conducted using information that is already present, in order to form an understanding on an observation, which is the method being applied in this research study, through literature contained in academic journals and published books, on both virtual organisation and the COVID-19 pandemic, in order to formulate an understanding on the phenomena pertaining to work-life balance.

In summary of the above, this research study is aimed at formulating an understanding on the worklife balance of employee's party to virtual organisations as a result of the COVID- 19 pandemic, which is done under the premise of the positivism research paradigm and makes use of qualitative research to ensure that the research study is descriptive and conceptual.

\section{Research Results and Findings}

Wolor et al. (2020: 445) defines work-life balance as "the balance between time someone spends working, compared to the time spent on one's personal life". In terms of this research, work-life balance is the single most important factor when analysing literature on the impact that the COVID-19 pandemic has had on working citizens, as it is their work-life balance that has been severely impacted.

At the start of 2020, the COVID-19 virus started to spread through various countries across the globe. In order to try and curb the COVID-19 infection rate, various countries implemented lockdown rulings that encouraged, and often mandated, corporate employees to work from home (in the South African context, it was only essential workers that took exception to stay-home mandate). As a result, over 3.4 billion people in 84 countries were confined to their homes before the start of April 2020 (Bouziri et al., 2020:509). Traditional companies who employed workers to work at a specific geographic location, were now newly established virtual organisations. Scherling and Lind (2021:60) notes that there are major differences between the establishment of a virtual teams or companies from nothing, with a view to 
conduct business as a traditional virtual organisation, and those establishing a virtual team whose members had experience working together and co-located in the same geographical location. Both have their own unique benefits and challenges. It is the latter that this research has chosen to focus on, as it is these virtual teams and, new virtual organisations, that have been established as a result of the restrictions placed on the business environment, due to the COVID-19 pandemic. This drastic, unplanned change in working conditions occurred rapidly and was considered to be drastic in the sense of employees adapting to new working conditions, as well as an entirely new livelihood in how they went about living their daily lives (Scherling \& Lind, 2021:60). With this being the case, it was crucial for companies to implement strategic steps pertaining to access to technology of employees working from home so that they had the required resources to do so, as well as ensuring that employees maintain a fair work-life balance as to ensure the motivation and performance of these employees (Wolor et al., 2020:449).

With companies strategically provided their employees with technology, millions of people were exposed to telecommuting as a means of access to a virtual working environment (Bouziri et al., 2020:509). This already proved to be a change relatively easy to implement, as Information and Communication Technologies (ICT's) became inveterate in traditional workspaces. Employees were able to alter the way they used this technology, with relative ease (Scherling \& Lind, 2021:60). The majority of employees were not less efficient in their personal productivity. There was no decrease in team performance, due to this familiarity with the inner workings of the technology at hand as employees been co-located before any virtual teams were established (Scherling \& Lind, 2021:60).

Concerns were raised relating to the sudden establishment of virtual teams or organisations severally impacting on the work-life balance of new virtual employees. Dockery and Bawa (2020:3) found that employees working for newly established virtual teams, as a result of COVID-19 restrictions, tend to work longer hours as there is no disconnect between work-life and home-life. Working from home, and the longer hours accompany the lifestyle, seemingly enhanced family conflict within the household (Dockery \& Bawa, 2020:3).

A further aspect identified was blurring of the roles within the family dynamic during the COVID-19 pandemic. Parents took on roles such as teacher, as well as caretaker, which would have not been the case pre-COVID-19. When these roles are in conflict with one another, the employee (the parent) is forced to compromise one role for another, which can create further conflict and stress within the household (Dockery \& Bawa, 2020:3). Dockery and Bawa (2020:3) outline the existing literature as continuously indicating the ability of virtual work to either reduce or exacerbate the stress of the employee, especially in relation to possible family and household conflict if the employee does not implement boundaries and carries out virtual work in a reasonable manner.

The overall literature seems to point toward the understanding that working virtually during the COVID-19 pandemic proved more positive for the majority of virtual employees. Further to this, literature provides overwhelming indication that the work-life balance of employees increased during this time. Wolor et al (2020:449) indicates that the work-life balance, and motivation that comes with employees working virtually during the COVID-19 pandemic, had a significant positive impact on employee performance. This is echoed by the literature contributed by Dockery and Bawa (2020:3) outlining the fact working virtually during the pandemic led to a $13 \%$ increase in the work performance of employees.

Authors Putri and Amran (2021:33) concluded that virtual work has the potential to negatively impact the work-life balance of employees, if not carried out correctly, but yields a significant and positive affect when it is. These authors added that an increase in the application of virtual work, will provide a further increase in the work-life balance of an employee (Putri \& Amran, 2021:33). It is therefore clear that employees who undertook to work virtually during the pandemic seems more satisfied in their ability to balance work and family life and experience an overall increase in job satisfaction.

However, in order to formulate a holistic understanding of the work-life balance of employee's party to virtual organisations as a result of the restrictions that have been placed on the business sector due to the COVID-19 pandemic, this research has formulated and combined the most frequent benefits and challenges pertaining to the work-life balance of the employees, based on the current literature. 


\subsection{Benefits}

Perhaps the most pertinent benefit, and most widely accepted according to the literature, is these virtual employees, working during the COVID-19 pandemic, are ultimately provided with a greater worklife balance as more time is spent with their families. This is due to the fact that employees are saving on commuting time, which afforded the opportunity to devote more time to other family activities, as well as productive activities (Dockery \& Bawa, 2020:3). Dockery and Bawa (2020:3) note that this, in itself, creates benefits such as virtual employees incurring direct financial saving due to their lack of commuting.

The digitalisation of work and processes accelerated as employees digitalised in order to ensure that the flow of work was not interrupted, and targets were not missed whilst working in the virtual environment (Scherling \& Lind, 2021:60). This led to an additional benefit that authors agreed on which is the scale and speed of knowledge sharing between employees drastically increasing within the virtual working environment during the pandemic (Scherling \& Lind, 2021:60). The communication between employees became more direct and clearer (Scherling \& Lind, 2021: 62).

All three of these benefits directly relate to the advancement in work-life balance of employees, as the ease of work and communication allowed for a higher job satisfaction, as well as the advancement in timesaving business practices. Employees completed tasks a more frequent rate, allowing more time to spend on non-work-related activities.

The final two benefits that are prevalent in the current literature are:

Newly virtual employees working during the pandemic were exposed to a unique situation wherein they had a greater discretion in deciding the times that they worked, as well as the pace at which they wanted to work at (Dockery \& Bawa, 2020:3). This directly influences the work-life balance of the employee, as it is ultimately their decision on when they preferred to work.

A further decrease in the work-family conflict that employees experienced before they worked in a virtual setting (Dockery \& Bawa, 2020:4).

The benefits that outlined proved to be the most frequent benefits occurring throughout the research in the current literature.

\subsection{Challenges}

One of the biggest challenges that authors agree on, in terms of employees working from home in a virtual setting due to the pandemic, is the sheer timing of the necessity for companies to have to conform to this virtual organisational structure. This drastic shift to working virtually had occurred at an anxietyprovoking time as a result of the pandemic and the uncertainty that came with it (Bouziri et al., 2020:509). This initial shift took some time for the worker to get used to, as it is a different environment the employee is exposed to than before, which may negatively impact the initial work-life balance of these employees. Authors further agree that the readiness (and even safety) of the home or virtual working environment was not guaranteed and ensured, as the sudden and drastic shift could not have been anticipated by these employees (Bouziri et al., 2020:509). The anxiety and stress that had accompanied this shift was a prodigious factor as to why the initial work-life balance of these virtual employees was low and perceived to be negative.

Along with this shift into a new home or virtual working environment, employees, who were also parents, were pushed into new roles and family dynamics as school closures resulted in parents having to care for their children and work virtually at the same time (Bouziri et al., 2020:509). This, again, had a major negative impact on the work-life balance of these virtual employees, as these employees to provide the same time to two completely different roles, which would also lead to further stress placed on the employee.

The above challenges all relate to the initial shift of employees taking up virtual work, and although there is evidence that these challenges are still relevant in the lives of virtual employees, the general consensus among authors is that these challenges and difficulties were greatly reduced once enough time had passed for these employees to grasp and get used to their new working reality. However, current challenges that are still being faced by these employees include the difficulty, and sometimes inability, for virtual workers to disengage from their work in their homework environment and ensure that a clear 
boundary is set between the work and non-work domains, respectively (Dockery \& Bawa, 2020:3). This has an obvious impact of the work-life balance of virtual employees, as it is these lines that are being blurred. Further, the opposite situation is also found to occur, wherein, because these employees are working in their home environment, there is a lower motivation to work, resulting in the life aspect of work-life balance taking precedent at the detriment to the work aspect (Dockery \& Bawa, 2020:4).

The challenges that have been outlined prove to be the most frequent challenges that have occurred throughout the research on the current literature, leading to the conclusions that these make up the main challenges and issues of the work-life balance of employees working from home in a virtual setting, as a result of the various restrictions placed on the global business sector due to the COVID-19 pandemic.

\section{Conclusion}

This conceptual research paper set out to provide an understanding of the work-life balance of employee's party to virtual organisations, as a result of the restrictions that have been placed on the business sector due to the COVID-19 pandemic. The findings provided general conclusions on the worklife balance of virtual employees, as well as an in-depth review on what various authors deemed to be the benefits and challenges of the work-life balance of these employees, in order to provide a more holistic understanding of the research objective. To this end, the findings indicate that there are both various benefits and challenges that come with working virtually during the COVID-19 pandemic. However, it is clear, based on the evidence that seems to be overwhelmingly positive in this aspect, that these virtual employees have a greater and more positive work-life balance, whilst working virtually amid the worldwide COVID-19 pandemic. This is based on the fact that employees have had the chance to spend more time with their families whilst working from home, communication between virtual employees being more direct and the digitalisation of shared knowledge leading to a greater amount of time saved leading to employees have more time for non-work activities, the financial cost saving that comes with working virtually, and the decrease in work-family conflict. In order to ensure that employees who are working virtually attain and maintain a greater work-life balance, the general consensus among authors, as outlined throughout this research, is for virtual employees to set clear boundaries and working hours for themselves at home, as well as delineate between work and non-work domains.

\section{Recommended Future Research}

Due to the COVID-19 pandemic being an ongoing occurrence, as well as fluctuating in its severity, topics that are centred around the aspects pertaining to it, such as virtual work, need to be constantly researched, as well as researched in different context (such as the differences of these aspects between different countries). At the time of this research contribution being written, the world has implemented various COVID-19 vaccine rollout plans, which, in theory, would allow for vaccinated workers to return to their central geographical working environment at their place of employment. However, further research can be conducted on the willingness of employees to do so, after working in a virtual environment that has allowed them to positively increase their work-life balance. Further research could also be conducted on the willingness of companies to reinitiate work at a central geographical working environment, when they themselves have saved costs (such as rent and utilities) and can see the positive impact that virtual work has had on their employees.

\section{References}

Alawamleh, M., and Ismail, L.B. (2016). Towards a Risk Management tool to support

collaboration in Virtual Enterprise. Organisational Studies and Innovation Review, 2(2): 28-35. Available at: https://www.researchgate.net/publication/319930843_Towards_a_Risk_Management_tool_to_support_collabo ration_in_Virtual_Enterprise [Accessed 21 May 2021]

Amorim, A.N.G.G. (2007). Virtual Organization Theory: Current Status and

Demands. Research Gate [online]. Available from: https://link.springer.com/content/pdf/10.1007\%2F978-0-38775466-6_1.pdf

Anthony, A.J., and Petersen, S.A. (2021). Examining the digitalisation of virtual enterprises amidst the COVID-19 pandemic: a systematic and meta-analysis. Enterprise Information Systems, 15(5): 617650.

Conference proceedings of the Centre for Business \& Economic Research, ROGE-2021, 9-10th December 
DOI: 10.1080/17517575.2020.1829075

Arntz, M., Berlingieri, F., and Sarra, B.Y. (2019). Working from Home:

HeterogeneousEffects on Hours Worked and Wages. SSRN Electronic Journal [online]. Available from: https:// papers.ssrn.com/sol3/papers.cfm?abstract_id $=3383408$

Aspers, P., and Corte, U. (2019). What is Qualitative in Qualitative Research. Qualitative Sociology, 42: 139-160. DOI: $10.1007 / \mathrm{s} 11133-019-9413-7$

Bajdor, P., Dagmara , B., and Lis, T. (2016). Management Of a Virtual Organisation from The Aspect of Creating Business Processes. microCAD International Multidisciplinary Scientific Conference, 1-6.

DOI:10.26649/musci.2016.050

Bouziri H., Smith, D.R.M., Descatha, A., Dab, W., and Jean, K. (2020). Working fromhome in the time of COVID-19: how to best preserve occupational health? Occupation Environmental Medical journal, 77(7): 509-510.

DOI: $10.1136 /$ oemed-2020-106599

Bryman, A., and Bell, E. (2015). Research Methodology: Business and Management Contexts. 5th Edition. Cape Town: Oxford University Press Southern Africa

Bui, P.A. (2020). The Roles of Leasers in Virtual Working Environment (Master's thesis). Oulu, Finland: Oulu University of Applied Sciences.

Available at: https://www.theseus.fi/bitstream/handle/10024/341263/Bui_Anh.pdf?sequence=2\&isAllowed=y

Butahieko, N., and Vyan, L. (2020). The impact of working from home during COVID-19 on work and life domains: an exploratory study on Hong Kong. TandFOnline.com [online]. Available from:

https://www.tandfonline.com/doi/full/10.1080/25741292.2020.1863560

Chumg, H.F., Seaton, J.S., and Cooke, L. (2016). Factors affecting employees' knowledge-sharing behaviour in the virtual organisation from the perspectives of well-being and organisational behaviour. Computers in Human Behaviour, 64: 432-448. DOI:10.1016/i.chb.2016.07.011

Čulo, K. (2016). Virtual Organisations - The Future Has Already Begun. Media, Culture and Public Relations, 1(7): $35-42$. Available at: VIRTUAL ORGANIZATION - THE FUTURE HAS ALREADY ...https://hrcak.srce.hr > file [Accessed 21 May 2021]

Deeb, G. (2020). The Pluses and Minuses of Virtual Teams. Forbes.com [online].

Available from:

https://www.forbes.com/sites/georgedeeb/2020/05/04/the-pluses--minuses-of-virtual-teams/?sh=117102483aba

Dockery, M., and Bawa, S. (2020). Working from Home in the COVID-19 Lockdown. Bankwest Curtin Economics Centre Research Brief, 5: 1-5

Available from: https://bcec.edu.au/assets/2020/05/BCEC-COVID19-Brief-4_Working-from-home.pdf [Accessed 12 July 2021]

Domazet, I., Marković, M.R., and Martinović, A.B. (2018). Digital Transformation: New Challenges and Business Opportunities. London: Silver and Smith Publishers

Dulebohn, J.H., and Hoch, J.E. (2017). Virtual Teams in Organisations. Human Resources Management Review, 27(4): 569574.

DOI:10.1016/j.hrmr.2016.12.004

Feitosa, j., and Salas, E. (2020). Today's Virtual Teams: Adapting Lessons Learned to The Pandemic. Elsevier Public Health Emergency Collection.

DOI: 10.1016/j.orgdyn.2020.100777

Garbe, A., Ogurlu, U., Logan, N., and Cook, P. (2020). COVID-19 and Remote Learning: Experiences of Parents with Children during the Pandemic. American Journal of Qualitative Research, 4(3), pp. 45-65.

https://doi.org/10.29333/ajqr/8471

Goodman, R. (2021). What Does Work-Life Balance Mean for Virtual Teams? RickGoodman.com [online]. Available from: https://www.rickgoodman.com/work-life-balance-mean-virtual-teams/

Grubb, A. (2021). An Ethnographic Study of Beneficent Boundaries in Virtual Voluntary Social Work. VOLUNTAS: International Journal of Voluntary and

Nonprofit Organizations, 1-11. DOI: 10.1007/s11266-021-00350-W

Hansen, J.P., Ipsen, C., Kirchner, K., and van Veldhoven M, (2021). Six Key Advantages and Disadvantages of Working from Home in Europe during COVID-19. International Journal of Environmental Research and Public Health [online]. Available from: https://www.mdpi.com/1660-4601/18/4/1826

Jaakkola, E. (2020). Designing conceptual articles: four approaches. AMS Review,

10: 18-26. Doi: 10.1007/s13162-020-00161-0

Jha, N., and Shenoy, V. (2018). Virtual Working and Work-Life Challenges of Virtual

Employees. Research Gate [online]. Available from:

Conference proceedings of the Centre for Business \& Economic Research, ROGE-2021, 9-10th December 
https://www.researchgate.net/publication/341385215_Virtual_Working_and_Work-

Life_Challenges_of_Virtual_Employees

Jimenez, A., Boehe, D.M., Taras, V., and Caprar, D.V. (2017). Working Across Boundaries: Current and Future Perspectives on Global Virtual Teams. Journal of International Management, 23(4).

DOI: 10.1016/j.intman.2017.05.001

Kerwin, T., and Radulovic, D. (2018). Digital Transformation: New Challenges and Business Opportunities. London: Silver and Smith Publishers

Koekemoer, E. (2020). Taking a new approach to work-life balance amid COVID-19 - UP professor offers employees and employers pointers (pg 1 - 3). UP.ac.za [online]. Available from:

https://www.up.ac.za/media/shared/799/2020/taking-a-new-approach-to-work-life-balance-amid-covid-19-upprof-offers-employees-and-employers-pointers.zp192716.pdf

Leimeister, J. M., Weigle, J. and Krcmar, H. (2001): Efficiency of Virtual Organisations the Case of AGI. Electronic Journal of Organizational Virtualness (eJOV), 3: 12-42.

Messenger, J.C., and Gschwind, L. (2016). Three Generations of Telework: New ICT's and the (R)evolution From Home Office to Virtual Office. New Technology, Work and Employment, 31(3): 195-208.

DOI:10.1111/ntwe.12073

Mihhailova, G., Õun, K., and Türk, K. (2009). Virtual work and its challenges and types. Business Review (Federal Reserve Bank of Philadelphia), 2(2): 96-103. Available from:

https://www.researchgate.net/publication/261144225_Virtual_work_and_its_challenges_and_types [Accessed 16 May 2021]

Putri, A., and Amran, A. (2021). Employees' Work-Life Balance Reviewed from Work from Home Aspect During COVID-19 Pandemic. International Journal of Management Science and Information Technology, 1(1): 30-34.

DOI: https://doi.org/10.35870/ijmsit.v1i1.231

Ryan, G. (2018). Introduction to positivism, interpretivism and critical theory. Nurse Researcher, 25(4): 4149.s:DPOI:10.7748/nr.2018.e1466

Scherling, D., and Lind, I.C. (2021). Digital Transformation and Virtual Team

Transition due to the COVID-19 Pandemic (Master's Thesis). Jönköping: Jönköping International Business School. Available from: http://hj.diva-portal.org/smash/get/diva2:1560965/FULLTEXT01.pdf [Accessed 11 July 2021]

Segal, J. (2013). A South African Perspective on Work-Life Balance: A Look at

Women in Academia. Wits.ac.za [online]. Available from:

http://wiredspace.wits.ac.za/jspui/bitstream/10539/13637/5/Final\%20research\%20project.pdf

Shenoy, V., and Jha, N. (2018). Virtual Working and Work-Life Challenges of Virtual

Employees. International Journal of Economic and Management, 8(5): 1-7. Available at: https://www.researchgate.net/publication/341385215_Virtual_Working_and_WorkLife_Challenges_of_Virtual_Employees [Accessed 16 May 2021][i[E]

Siedlecki, S.L. (2020). Understanding Descriptive Research Designs and Methods. Clinical Nurse Specialist, 34(1): 8-12. DOI: 10.1097/NUR.0000000000000493

Starner, T. (2016). For virtual employees, work-life 'integration' is the goal. HRDive.com [online]. Available from:

https://www.hrdive.com/news/for-virtual-employees-work-life-integration-is-the-goal/424492/

Thomas, G. F. (N.d.). Virtual Organisations: Background and context. References For Business [online]. Available from: https://www.referenceforbusiness.com/management/Tr-Z/Virtual-Organizations.html

Uddin, M. (2021). Addressing work-life balance challenges of working women during COVID-19 in Bangladesh. International Social Science Journal, 71(3).

DOI:10.1111/issi.12267

Waizennegger, L., McKenna, Brad., Cai, W., and Bendz, T. (2020). An affordance perspective of team collaboration and enforced working from home during COVID-19. European Journal of Information Systems, 29(4): 429-442.

DOI: 10.1080/0960085X.2020.1800417

Wolor, C.W., Solikhah, S., Fidhyallah, N.F., and Lesteri, D.P. (2020). Effectiveness of E-Training, E-Leadership, and Work Life Balance on Employee Performance during COVID-19. Journal of Asian Finance, Economics and Business, 7(10): 443-450. DOI:10.13106/jafeb.2020.vol7.no10.443

Zuofa, T., and Ochieng, E. (2017). Working separately but together: Appraising

virtual project team challenges. Team Performance Management: An International Journal, 3: 1-27. DOI: 10.1108/TPM-062016-0030 